Revue de droit comparé du travail et de la sécurité sociale

3 | 2018

La participation des travailleurs dans la grande entreprise privée et publique

\title{
L'adoption de la loi sur le télétravail
}

Felicia Roșioru

\section{OpenEdition}

Journals

Édition électronique

URL : https://journals.openedition.org/rdctss/1934

DOI : $10.4000 /$ rdctss. 1934

ISSN : 2262-9815

Éditeur

Centre de droit comparé du travail et de la sécurité sociale

Édition imprimée

Date de publication : 1 novembre 2018

Pagination : 186-189

ISSN : 2117-4350

\section{Référence électronique}

Felicia Roșioru, «L'adoption de la loi sur le télétravail », Revue de droit comparé du travail et de la sécurité sociale [En ligne], 3 | 2018, mis en ligne le 01 novembre 2021, consulté le 13 novembre 2021. URL: http://journals.openedition.org/rdctss/1934; DOI : https://doi.org/10.4000/rdctss.1934

\section{(c) $($ ) $(9)$}

Revue de droit comparé du travail et de la sécurité sociale est mise à disposition selon les termes de la Licence Creative Commons Attribution - Pas d'Utilisation Commerciale - Pas de Modification 4.0 International. 


\title{
FELICIA ROSIORU
}

\author{
Université Babes-Bolyal de Cluj-Napoca
}

\section{L'ADOPTION DE LA LOI SUR LE TÉLÉTRAVAIL}

Le changement législatif le plus notable concernant les relations de travail en Roumanie vise l'adoption de la loi sur le télétravail ${ }^{1}$, après plus de neuf mois de débat public. Avant l'adoption de cette loi, dans l'effort de modernisation du marché du travail, le Programme de Gouvernement 2017-2020 approuvé par le Parlement roumain avait prévu le télétravail comme modalité de flexibilisation des rapports de travail. Auparavant, le télétravail était considéré comme une forme de travail à domicile, réglementé par l'art. 108 - 110 du Code du travail, mais ses dispositions dans ce domaine s'accordaient mal avec la définition du lieu du travail, telle que contenue dans la loi n³19 du 2006 sur la santé et la sécurité au travail. En plus, la réglementation lapidaire contenue dans le Code du travail s'est avérée inadéquate par rapport aux spécificités du télétravail, le télétravailleur salarié était insuffisamment protégé et, dans ce contexte, la loi n 81/2018 a été adoptée. La protection minimale instaurée par la loi dans ce domaine peut être complétée par des dispositions plus favorables contenues dans les conventions collectives, le contrat du travail ou le règlement intérieur.

La loi n 81/2018 contient les définitions du télétravail et du «télésalarié » et s'applique, donc, uniquement aux rapports de travail salarié. Le télétravail est défini comme la forme d'organisation du travail par laquelle le salarié remplit de façon régulière et volontaire les tâches spécifiques à son emploi ou à sa profession dans un lieu autre que le lieu de travail organisé par l'employeur, au moins un jour par mois, en utilisant les technologies de l'information et de la communication. Le travail, qui peut aussi bien être réalisé dans les locaux de l'employeur, est effectué hors de ces locaux de façon régulière. La définition légale roumaine tient compte de l'approche large adoptée par les partenaires sociaux ${ }^{2}$ dans l'accord-cadre européen sur le télétravail, afin de couvrir différentes formes de télétravail régulier.

Cette forme d'organisation du travail se fonde sur la volonté des parties et doit être expressément prévue dans le contrat de travail. S'il n'a pas été convenu dès le début, le recours au télétravail entraîne la modification du contrat de travail par écrit pour permettre au salarié de télétravailler, sous peine d'amende, pour l'employeur, de $5000 \mathrm{lei}^{3}$. Le refus du salarié ne peut constituer un motif de modification unilatérale du contrat de travail par son employeur, ni une faute disciplinaire. L'employeur ne peut pas être contraint non plus d'accepter le télétravail et son refus ne peut pas être censuré, sauf en cas d'abus de droit.

1 Loi $n^{\circ} 81 / 201$ sur la réglementation du télétravail publiée dans le Moniteur Officiel $n^{\circ} 296$ du 2 avril 2018.

2 Il s'agit de la Confédération européenne des syndicats (CES), I'Union des confédérations de I'industrie et des employeurs d'Europe/Union européenne de l'artisanat et des petites et moyennes entreprises (UNICE/UEAPME) et le Centre européen des entreprises à participation publique (CEEP).

3 Ce qui équivaut environ à 1100 euros. 
La loi consacre, donc, en ligne avec l'accord-cadre européen sur le télétravail, le caractère volontaire de cette forme d'organisation du travail.

En ce que concerne la régularité du télétravail, il suffit que le télétravailleur salarié réalise son travail en utilisant les technologies de l'information hors les locaux de l'employeur un seul jour par mois pour bénéficier de la protection octroyée par la loi nº 81/2018. Cette protection étendue a été adoptée afin d'assurer à tout télétravailleur salarié le droit de gérer l'organisation de son temps de travail, ainsi que la protection de sa vie privée, mais elle peut poser des problèmes pour les employeurs, car la protection légale s'applique en fait même dans le cas du télétravail occasionnel ${ }^{4}$.

La loi se propose de combler plusieurs lacunes de la réglementation antérieure, notamment d'assurer une meilleure information du télétravailleur salarié et d'établir avec précision le temps de travail, pour permettre au télétravailleur salarié de délimiter sa vie personnelle de la vie professionnelle. L'avantage du télétravail consiste, parmi d'autres, dans le droit du télétravailleur salarié de gérer l'organisation de son temps de travail ; pourtant, selon la loi $n^{\circ} 81 / 2018$, les parties doivent mettre en place un horaire de travail. Le temps de travail est établi par l'accord des parties, conformément au contrat du travail, au règlement intérieur et / ou à la convention collective applicable et aux dispositions légales. La mise en place d'horaire de travail sert à l'inspection du travail pour vérifier si le télétravail n'est pas utilisé par l'employeur pour dépasser la durée maximale du travail. Sur demande de l'employeur et avec l'accord écrit du salarié, le télétravailleur peut effectuer des heures supplémentaires, rémunérées en tant que telles ${ }^{5}$.

Dans le cas où l'employeur recourt au télétravail, il a une obligation d'information étendue du salarié: le contrat de travail doit contenir des informations supplémentaires relatives à la période et/ou les jours où le salarié travaille dans le lieu de travail organisé par l'employeur, ainsi qu'au ou qu'aux lieux d'activité de télétravail agréés par les parties; le programme dans lequel l'employeur a le droit de vérifier l'activité du télétravailleur salarié et la manière concrète d'effectuer le contrôle.

Le contrat de travail doit aussi prévoir la manière de mettre en évidence les heures travaillées par le télétravailleur salarié; les responsabilités des parties, compte tenu du lieu de télétravail, y compris les responsabilités dans le domaine de la sécurité et de la santé au travail ; l'obligation de l'employeur d'assurer le transport des matériels utilisés par le salarié dans son activité, selon le cas; l'obligation pour l'employeur d'informer le télétravailleur salarié sur les dispositions légales, de la convention collective applicable et/ou du règlement intérieur concernant la protection des données à caractère personnel utilisées et traitées par le télétravailleur à des fins professionnelles, ainsi que de l'obligation du télétravailleur salarié de respecter ces dispositions; les mesures prises par l'employeur pour s'assurer que le télétravailleur salarié n'est pas isolé du reste des employés et qu'il / elle peut prendre des dispositions pour qu'ils rencontrent régulièrement des collègues; les conditions dans lesquelles l'employeur supporte les coûts du télétravail. En règle générale, l'employeur doit fournir, installer et entretenir les équipements nécessaires au

4 Le télétravail doit être expressément prévu dans le contrat de travail, sous peine d'amende, pour l'employeur, de 10000 lei (ce qui équivaut environ à 2200 euros).

5 Selon le Code du travail roumain, ces heures supplémentaires peuvent être converties en repos compensateur de remplacement payé d'une durée équivalente. Si la conversion n'est pas possible, la majoration prévue par le Code du travail ne peut être inférieure à $75 \%$. 
télétravail, mais le télétravailleur peut utiliser son propre équipement. L'employeur est tenu responsable, selon le Code du travail, de remplacer les équipements endommagés sans faute du travailleur, ainsi que de payer les coûts liés à la perte ou à l'endommagement des données utilisées par le télétravailleur

L'acte normatif prévoit des obligations renforcées de l'employeur dans le domaine de la santé et de la sécurité du télétravailleur salarié et, en règle générale, vise à assurer à celui-ci la même protection globale qu'aux travailleurs qui exercent leurs activités dans les locaux de l'entreprise. En plus, la loi se propose d'assurer la conciliation les besoins de flexibilité et sécurité communs aux employeurs et aux télétravailleurs salariés.

En matière de sécurité et de santé au travail, l'employeur a quelques obligations spécifiques, notamment de fournir les moyens de technologie de l'information et de la communication et/ou l'équipement de travail sûr, nécessaire à l'accomplissement des tâches professionnelles, à moins que les parties n'en conviennent autrement ; d'installer, inspecter et entretenir l'équipement de travail requis, sauf accord contraire des parties; de veiller à ce que les télétravailleurs salariés reçoivent une formation adéquate en matière de sécurité et de santé au travail, notamment sous la forme d'informations et d'instructions de travail spécifiques au lieu de télétravail et à l'utilisation des écrans de visualisation. A son tour, le télétravailleur qui remplit les tâches spécifiques à son emploi en utilisant les technologies de l'information et de la communication doit respecter les dispositions légales et les instructions de l'employeur afin de ne pas s'exposer, ni d'autres personnes, à des risques d'accident ou de maladie professionnelle. En particulier, le télésalarié a l'obligation d'informer l'employeur sur les équipements de travail utilisés et les conditions du lieu de télétravail, de lui permettre d'accéder autant que possible à la mise en œuvre des mesures de sécurité et de santé au travail conformément aux clauses du contrat de travail ou pour mener des enquêtes sur les accidents de travail; de ne pas modifier les conditions de sécurité et de santé sur le lieu de télétravail; de n'utiliser que des équipements de travail ne présentant aucun danger pour sa santé et sa sécurité.

Le télétravailleur salarié a l'obligation de respecter les règles et restrictions spécifiques établies par l'employeur en ce qui concerne les réseaux Internet utilisés ou l'utilisation des équipements fournis par l'employeur. L'employeur a l'obligation, selon la législation nationale, de prendre les mesures nécessaires pour assurer la protection des données utilisées et traitées par le télétravailleur à des fins professionnelles et d'informer le télétravailleur salarié de toute restriction lié à l'usage des équipements.

Afin de vérifier l'application correcte des dispositions applicables en matière de santé et de sécurité et des rapports de travail, la loi prévoit le droit de l'employeur et/ou des autorités compétentes d'accès au lieu du télétravail. Les représentants du syndicat, ainsi que les représentants élus des travailleurs ont aussi un droit d'accès au lieu du télétravail afin de vérifier les conditions de travail du télétravailleur salarié, dans les limites des conventions collectives applicables, du contrat de travail ou du règlement intérieur, selon le cas. Si le télétravailleur travaille à domicile, le droit d'accès est soumis à une notification préalable et à son accord.

Même si la loi ne le prévoit pas expressément, conformément au principe d'égalité de traitement gouvernant les rapports de travail entre le télétravailleur salarié et son employeur, le télétravailleur a le même droit d'accès à la formation et aux possibilités de carrière que des travailleurs comparables qui travaillent dans les locaux de l'employeur ; il est soumis aux mêmes politiques d'évaluation que ces autres travailleurs, en tenant compte 
de la même charge de travail et des critères de résultats du télétravailleur équivalents à ceux de travailleurs comparables dans les locaux de l'employeur. Le principe d'égalité s'applique aussi dans le domaine des droits collectifs des télétravailleurs, qui sont les mêmes que ceux des travailleurs dans les locaux de l'entreprise. Le télétravail ne doit pas constituer un obstacle à la communication avec les représentants des travailleurs. Selon la loi $n^{\circ} 81 / 2018$, le télétravailleur salarié bénéficie de tous les droits prévus par la loi, le règlement intérieur et les conventions collectives pour les travailleurs comparables dans les locaux de l'employeur. Les conventions collectives, le règlement intérieur ou le contrat de travail peuvent prévoir des droits spécifiques aux télétravailleurs, compte tenu des conditions spécifiques du télétravail. 